\title{
Mapping of Neuropeptide Y Expression in Octopus Brains
}

1 Running Title: Neuropeptide Y in Octopus Brains

2 Gabrielle C. Winters ${ }^{1}$, Gianluca Polese ${ }^{2}$, Anna Di Cosmo ${ }^{2 *}$, Leonid L. Moroz ${ }^{1,3^{*}}$

$3{ }^{1}$ Whitney Laboratory for Marine Biosciences, University of Florida, St. Augustine, FL,

4 32080, USA;

$5 \quad{ }^{2}$ Di Cosmo Laboratory, University of Napoli Federico II, Department of Biology, Napoli,

6 Italy

$7{ }^{3}$ Departments of Neuroscience and McKnight Brain Institute, University of Florida,

8 Gainesville, FL, 32610, USA.

9

10 * Correspondence:

11 Leonid L. Moroz: $\underline{\text { moroz@ whitney.ufl.edu }}$

12 The Whitney Laboratory, 9505 Ocean Shore Blvd, St Augustine FL, 32086, USA

13 Anna Di Cosmo: dicosmo@unina.it

14 
15 Abstract

16 Neuropeptide Y (NPY) is an evolutionarily conserved neurosecretory molecule implicated

17 in a diverse complement of functions across taxa and in regulating feeding behavior and

18 reproductive maturation in Octopus. However, little is known about the precise molecular

19 circuitry of NPY-mediated behaviors and physiological processes, which likely involve a

20 complex interaction of multiple signal molecules in specific brain regions. Here we examined

21 the expression of NPY throughout the Octopus central nervous system. The sequence

22 analysis of Octopus NPY precursor confirmed the presence of both signal peptide and

23 putative active peptides, which are highly conserved across bilaterians. In situ hybridization

24 revealed distinct expression of NPY in specialized compartments, including potential

25 "integration centers," where visual, tactile, and other behavioral circuitries converge. These

26 centers integrating separate circuits may maintain and modulate learning and memory or

27 other behaviors not yet attributed to NPY-dependent modulation in Octopus. Extrasomatic

28 localization of NPY mRNA in the neurites of specific neuron populations in the brain

29 suggests a potential demand for immediate translation at synapses and a crucial temporal role

30 for NPY in these cell populations. We also verified the presence of NPY mRNA in a small

31 cell population in the olfactory lobe, which is a component of the Octopus feeding and

32 reproductive control centers. However, the molecular mapping of NPY expression only

33 partially overlapped with that produced by immunohistochemistry in previous studies. Our

34 study provides a precise molecular map of NPY mRNA expression that can be used to design

35 and test future hypotheses about molecular signaling in various Octopus behaviors.

36 Keywords: neuropeptide, cephalopod, Nautilus, nervous system evolution, feeding,

37 reproduction 
39 Research Highlights/Graphical Abstract text:

40 Neuropeptide Y (NPY), an evolutionarily conserved neurosecretory molecule, is expressed

41 in specialized regions of the Octopus brain controlling feeding, reproduction, and visual and

42 tactile memory circuits. Extrasomatic mRNAs were found in neurites, suggesting synaptic 43 synthesis of NPY.

44

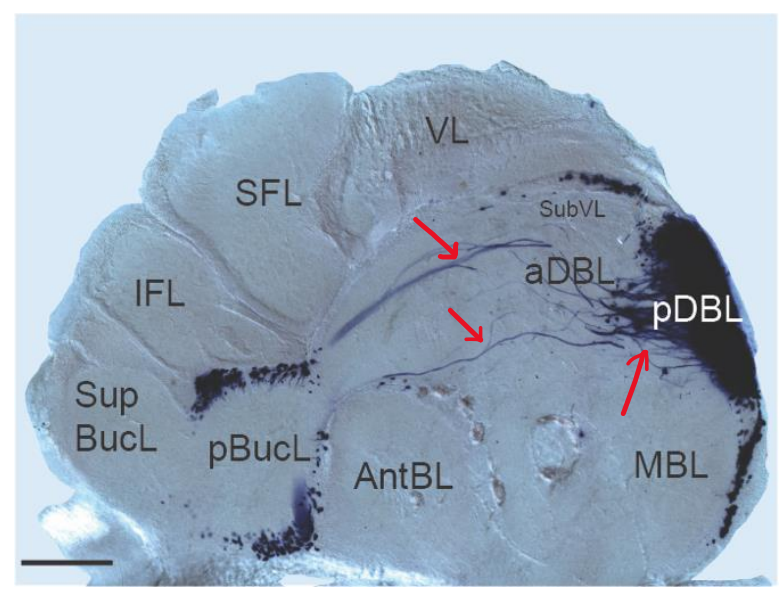

45 


\section{Introduction}

A diverse array of functions have been attributed to the 36-amino acid polypeptide Neuropeptide Y (NPY) (Thorsell et al., 2001) since its initial discovery in mammals in 1982 (Tatemoto K Fau - Carlquist et al., 1982), including digestive (Cox, 1993), cognitive (Redrobe et al.), and cardiovascular (Walker et al., 1991) processes. Several interdisciplinary studies have revealed shared functions of NPY in controlling metabolic states (Ruffin et al., 1997, Beck, 2006, Holzer et al., 2012, Salomäki-Myftari et al., 2016, Fadda et al., 2019), circadian rhythms (Albers et al., 1984, Yannielli et al., 2001, Erion et al., 2016) and stress/anxiety (Wahlestedt et al., 1993, Thorsell et al., 2002, Wu et al., 2003) responses across diverse taxa, but whether these functional commonalities are the result of evolutionary conservation or independent recruitment is yet unknown.

The role of NPY in the regulation of feeding and satiety has been explored in both protostome and deuterostome taxa since the 1990s (Hanson et al., 1995). One extensively conserved role for NPY is as an orexigenic (appetite-stimulating) factor
(Beck, 2006, Christie et al., 2011, Di Cristo et al., 2017, Fadda et al., 2019). This has been examined closely in the fly Drosophila melanogaster, where Neuropeptide F (D. melanogaster NPY ortholog) neurons were shown to regulate many aspects of feeding, including olfactory learning (Rohwedder et al., 2015) and temporal foraging behavioral shifts (Wu et al., 2003) in larvae, motivational control of appetitive memory in the mushroom bodies of adults (Krashes et al., 2009), and central modulation of peripheral olfactory responses (Lee et al., 2017). NPF/NPY expression has also been associated with diminished stress, fear, and anxiety responses in both mammals (Wahlestedt et al., 1993, Thorsell et al., 2002) and fruit flies (Wu et al., 2003). NPF in fruit flies also mediates clockregulated sex dimorphic behavior (Lee et al., 2006) and circadian gene expression (Erion et al., 2016).

Neuropeptide Y orthologs have been identified and functionally characterized in representatives from three classes of the phylum Mollusca: Cephalopoda, Bivalvia, and Gastropoda. Injection of purified NPY (aka NPF) ligand into the saltwater Manila clam (a 
bivalve) Ruditapes philippinarum, increased filtration rates, which presumably increased nutrient acquisition (Wang et al., 2017). The roles role for NPY homologs in gastropods appears to vary by taxa. In the pond snail, Lymnaea stagnalis, administration of NPY appeared to inhibit both growth and reproduction but had no discernible effect on the intake of food (de Jong-Brink et al., 2001). Neuropeptide $\mathrm{Y}$ injections in the gastropod Aplysia californica surprisingly reduced food intake, and its activity appears to be a key element in the feeding network reconfiguration as the animal's motivational state shifts from hunger to satiety (Jing et al., 2007). Therefore, the role of NPY in molluscs is not entirely conserved but consistently plays some role in mediating the acquisition and/or digestion of nutrients.

One proposed function of NPY in Octopus is as a candidate messenger mediating the temporal shift between growth and reproductive life stages, which is an essential part of their ecological life history (Di Cosmo et al., 2014, Polese et $a l ., 2015)$. The transition from hunting and feeding behaviors to Octopus sexual maturity is irreversible in nature
(Wodinsky, 1977, Boyle, 1983); it is hormone-controlled, and must only occur once the individual's lifetime nutritional needs have been met (De Lisa et al., 2012, Di Cosmo et al., 2014, Polese et al., 2015). Gametogenesis and subsequent reproductive processes are energetically demanding in females, and in many cases controlled by an array of hormones and other secretory molecules that initiate senescence and, ultimately, death (Boyle, 1983, De Lisa et al., 2012, Di Cosmo et al., 2013, Di Cosmo et al., 2016). Upon sexual maturation, the metabolic requirements of the reproductive system overtake the demands of somatic tissues (Di Cosmo et al., 2013). Only after an animal accumulates sufficient nutrient reserves to meet reproductive demands do specialized signals to growth and reproduction neural centers induce a shift from the feeding state to the reproductive life stage (Wodinsky, 1977, Boyle, 1983).

The primary CNS structures composing the growth and reproduction 
control centers are the olfactory lobes ${ }^{1}(\mathrm{Di}$ Cosmo et al., 1998, Di Cosmo et al., 2014, Polese et al., 2015) and optic glands (Wells et al., 1959, Wells, 1978, Juárez et al., 2019, Wang et al., 2019), both located between the brain and the hilum of each optic lobe on the optic stalks. The subpedunculate lobes, located in the posterior/dorsal region below the subvertical lobe, are also involved in the central control of these physiological processes. A current model (Di Cristo, 2013, Di Cosmo et al., 2014, Polese et al., 2015) for feeding and reproduction regulation in Octopus implies recruitment of multiple neuropeptides and neurohormones including FMRFamide (Di Cosmo et al., 1998, Suzuki et al., 2002), Gonadotropin-releasing hormone (GnRH) (Di Cosmo et al., 1998, Di Cristo et al., 2009), Galanin (Suzuki et al., 2000) and Neuropeptide Y (Suzuki et al., 2002) (NPY). Briefly, this model suggests that the olfactory lobes receive information about an individual's energy stores/demands, and this input determines

\footnotetext{
${ }^{1}$ It is important to note that the term "olfactory lobe" was designated to this structure because of its direct anatomical connection to an olfactory organ, and does not imply that the only function of the
}

whether neurons in the olfactory lobe produce Neuropeptide Y (NPY): a primary candidate messenger for optic gland inhibition. To date, the mechanism by which the NPY-producing neurons of the olfactory lobe receive satiation input is still unknown. According to this model, if the individual has not accumulated needed energy reserves, NPY is constitutively produced by the olfactory lobe, maintaining the animal's appetite so Octopus can continue to feed and grow. Once lifetime energy demands are met, Neuropeptide $Y$ production ceases in the olfactory lobe, and the olfactory lobe peptides $\mathrm{GnRH}$ and Galanin activate the optic gland (Di Cosmo et al., 2014); the animal can enter the reproductive life stage. The optic gland then produces a yet undescribed trophic factor(s) that can activate the process of gonadal maturation and the onset of mating behaviors. Thus, the specific roles and, in particular, localized expression of neuropeptides and neurohormones are critical to

lobe is "olfactory" or that all neurons housed here play a direct role in chemosensation. The specific function(s) of this lobe are likely diverse and still being elucidated. 
understanding the mechanistic control of feeding and reproduction.

Here, we have focused on exploring the region-specific expression and distribution of Neuropeptide $\mathrm{Y}$ in Octopus. By cloning and characterizing the Octopus NPY precursor, we mapped the expression of mRNA transcripts encoding neuropeptide $\mathrm{Y}$ prohormone (pNPY- the precursor to the active peptide NPY) throughout the entire central nervous system. These experiments have provided molecular insights to existing models for mediation of feeding and reproduction, as well as presented novel information that can be used to generate hypotheses and future studies geared toward deciphering functional roles for NPY in Octopus.

\section{Materials and Methods}

We obtained the DNA sequence for Octopus vulgaris Pro-neuropeptide $Y$ $(O v p N P Y)$ from our Illumina sequencing data (BioSample Accession number SAMN09698694) using tblastn (Basic Local Alignment Search Tool (Altschul et $a l ., 1990)$ using a protein query to search a DNA database) with the protein sequence from Lymnaea stagnalis (CAB63265.1) as a probe. The coding region of the sequence (flanked by sequences specific to $\mathrm{T} 7$ (Roche T7 RNA polymerase Sigma cat no 1088176700) and T3 (Roche T3 RNA polymerase-Sigma cat no 11031163001) promoters, and Not1 (NEB cat no R3189S) and Pme1 (NEB cat no R0560S) restriction enzymes) was synthesized into a pUC57 plasmid DNA vector by Genscript®.

\section{Animal Acquisition and Preparation}

Due to the limited availability of Octopus vulgaris, we elected to use the readily available species Octopus bimaculoides for expression localization studies. Nucleotide sequences for ObpNPY and OvpNPY share 97\% identity, so probes generated using the synthesized OvpNPY sequence were sufficiently similar and specific in both species.

Six wild-caught adults $>50 \mathrm{~g}$ Octopus bimaculoides were shipped overnight to our laboratory from Marinus Scientific in Long Beach, CA, in Summer 2016. Octopuses were anesthetized with either $337 \mathrm{mM} \mathrm{MgCl}_{2}, 10 \%$ ethanol $(\mathrm{EtOH})$ in the filtered seawater (FSW) on 
ice, or placed directly on ice for euthanasia. Neuronal tissues (Brain, Optic Lobes, Arm Cords, and Stellate Ganglia were extracted and fixed in $4 \%$ paraformaldehyde (PFA) in FSW for subsequent in situ hybridization.

The experiments in the present study were conducted in accordance with the principles and procedures that were approved by the Institutional Animal Care of University on Naples Federico II (Project $n^{\circ}$ 608/2016-PR- 17/06/2016; protocol n. DGSAF 0022292-P03/10/2017), and according to the Italian and European law (European Directive 2010/63 EU L276; Italian DL. 4/03/2014, no. 26; the ethical principles of Reduction, Refinement, and Replacement).

\section{Probe Preparation}

All Digoxygenin (DIG) labeled probes were generated using the Roche DIG labeling kit (Sigma Cat no 11277073910). Antisense probes were generated using Pmel (NEB cat no R0560S) restriction enzyme followed by T7 RNA polymerase (Sigma cat no 10881767001). Final probes were cleaned up using RNeasy MinElute Cleanup Kit (Qiagen Cat No./ID: 74204), and one microliter was visualized on a $2 \%$ agarose gel to estimate concentration.

\section{NPY in situ hybridization}

The procedure for in situ hybridization was based on a modified protocol for Aplysia californica described previously (Jezzini et al., 2005, Antonov et al., 2007, Moroz et al., 2013). Dissected neuronal tissues from six individual octopuses were removed whole and incubated in $4 \%$ paraformaldehyde (PFA) in phosphate-buffered saline (PBS) at $4^{\circ} \mathrm{C}$ for three hours. Tissues were then rinsed in PBS before slicing at 175 (brain) or 250 (other tissues) micrometer thickness on a vibratome. Slices were then fixed overnight in $4 \%$ PFA in phosphatebuffered saline (PBS) at $4^{\circ} \mathrm{C}$. The following day slices were dehydrated stepwise and stored in $100 \%$ methanol until use (up to three weeks).

Next, dehydrated tissue slices were rehydrated stepwise and taken through a series of washes to optimize permeability. After prehybridization, probes were added at a concentration of $1 \mu \mathrm{g} / \mu \mathrm{L}$ in hybridization buffer, and tissues were incubated overnight at $50^{\circ} \mathrm{C}$. Next, after a series of washes and blocking steps, 
tissues were incubated at $4{ }^{\circ} \mathrm{C}$ in a solution of $0.05 \%$ alkaline phosphatase-conjugated DIG antibodies (Roche cat \#11093274910) overnight. After a final series of washes, the tissues were incubated in $20 \mu \mathrm{L}$ NBT/BCIP per $1 \mathrm{~mL}$ detection buffer. Upon development completion, the tissues were incubated in 4\% PFA in $\mathrm{MeOH}$ for 40-60 minutes and washed twice in $100 \%$ EtOH before being stored in $100 \% \mathrm{EtOH}$ or mounted on a slide using methyl salicylate and Permount.

\section{Microscopy and Imaging}

Images of tissue preparations were taken with a Qimaging Retiga EXi Fast1394 digital camera mounted on a Nikon TE-2000E microscope using DIC settings using with NIS Elements software V4.3. Whole images were enhanced for clarity in Adobe Photoshop. Figures were created using Adobe Illustrator and Microsoft PowerPoint.

\section{Protein Sequence and Structural Analyses}

General domain architecture for pNPY protein sequences was determined using the Simple Modular Architecture
Research Tool (SMART) (Letunic et al., 2015, Letunic et al., 2018). Domain features not predicted by SMART (e.g., glycine residues to indicate amidation sites and cleavage sites) were identified visually from the protein sequence alignment. This alignment was created using default parameters in Muscle (Edgar, 2004). Selected sequences were identified using BLASTp (Altschul et al., 1990) searches on NCBI. The molecular phylogenetic analysis was completed by using the Maximum Likelihood method based on the Whelan And Goldman model (Whelan et al., 2001). We depicted an image of the tree with the greatest $\log$ likelihood (-1477.4407). The bootstrap value (the percentage iterations in which the clustered taxa were associated with one another) is shown next to each node, except for those for which the value was below 50. Neighbor-Join and BioNJ algorithms were applied to a matrix of pairwise distances estimated using a JTT model to generate initial trees for the heuristic search. Then topology with superior log likelihood value was selected. Branch lengths correspond to the number of substitutions per site. These evolutionary analyses were conducted in 
MEGA7(Kumar et al., 2016). Figures were created using Adobe Creative Suite ${ }^{\circledR}$.

\section{Results}

Neuropeptide $Y$ as one of few evolutionarily conserved neuropeptides in Bilateria

Genes encoding the precursor of neuropeptide $\mathrm{Y}$ were only identified in protostomes and deuterostomes; they are absent in non-bilaterians sequenced so far (Ctenophora, Porifera, Cnidaria, Placozoa). Multiple sequence alignments (Figure 1a) revealed amino acid sequences of the NPY prohormone are highly conserved across bilaterians, particularly in the putative active sites (bioactive peptide after posttranslational modifications like cleavage (by prohormone convertases) and amidation (by peptidylglycine alpha-amidating monooxygenase (PAM) enzyme). The sequence for the predicted bioactive peptide for $O$. bimaculoides NPY shares $86 \%$ identity with both cephalopod species Nautilus pompilius and Doryteuthis pealei, as well as $72 \%$ with that of the gastropod Aplysia californica, and 27\% with that of Homo sapiens. Beyond the putative NPY active site, sequence conservation is relatively low in signal peptide domains and $\mathrm{C}$-termini. The $O$. bimaculoides predicted bioactive NPY peptide

is

MLAPPNRPSEFRSPEELRKYLKALNE YYAIVGRPRF-amide.

\section{Highly-localized expression of pNPY mRNA in the Octopus bimaculoides brain}

NPY precursor-encoding transcripts (pNPY) appear to be expressed in very densely packed neurons of the dorsal basal lobe (DBL), subvertical lobes (SubVL), and in the moderately densely packed cell somata layer of the posterior buccal lobe. Thick projections extend up to $2 \mathrm{~mm}$ from the middle of the superior dorsal region of the DBL (Figure 2a) and are wide enough to be visible in a coronal cross-section through basal lobes below the vertical lobe (Figure 2d). Expression of pNPY encoding transcript appears absent in all other lobes except for a few large cells scattered at the periphery of the anterior basal lobe (Figure 2a). 
pNPY is expressed in the Dorsal Basal and the Subvertical lobes

Seven morphologically distinct neuronal subtypes were identified (Table 1), expressing pNPY transcripts in the dorsal basal and subvertical lobes. Neurons with exceptionally long and thick pNPY-containing neurites originated in the middle of the superior dorsal region of the DBL (type 1) (Figures 2a, 3a and 3b), while neurons in the inferior/posterior cell somata layer of the DBL and median basal lobe (MBL) were relatively large (type 5; Figure $3 f$ and $3 g$ ) and their processes are relatively short if present at all. The somata of all pNPY-containing neurons with the long thick processes (type 1) were clustered densely and appeared indistinguishable from one another, except for the neuronal soma indicated by the closed arrow in Figure 3b. Smaller neurons expressing pNPY are densely clustered in the subvertical lobe (type 6 in Figure 3e). Most of these neurons have no visible neurites recognized by $\mathrm{pNPY}$ probes.

The posterior region of the DBL (superior to the majority of the long projecting neurons (type 1), but inferior to the subvertical lobes) contains two distinct types of small neurons. The first, type 2, has an irregular triangle shape and no visible processes (indicated by the chevron-shaped arrow in Figures $3 e$ and 3h), the second (type 3) has an irregular teardrop shape with short projections that are approximately half-length of the soma (indicated by the closed arrowhead arrow in Figures 3e and 3h). Amongst the large thick processes of pNPY neurons, type 4 are tapered oval (guitar pick) shaped neurons (indicated by thick line closed arrows in Figure 3c), some of which have visible punctate projections (indicated by thinner line closed arrows in Figure 3d).

\section{pNPY expression in the Posterior}

\section{Buccal Lobe}

Two distinct subtypes of neurons express pNPY encoding transcripts in the cell somata layer of the posterior buccal lobes (pBucL) (Table 1). These neurons are generally clustered densely together. Figure 4 shows the density and arrangement of pNPY positive cells. The pBucL neurons had a teardrop shape with kinked projections, typically pointing toward the neuropil that measures approximately equal to the length of their somata (Type 7 in table 1). These neurons 
exhibit a wide range of sizes (from 10 to 35 micrometers in soma length), as is depicted by the colored arrows in Figure 4b. In general, the larger neuronal somata were located toward the periphery of the cell somata layer, and the smaller ones were located toward the middle or (in fewer cases) adjacent to the neuropil. An additional class of smaller (type 8 in Table 1, 5-15 micrometer length cell somata) irregular oval-shaped neurons expressed pNPY (closed arrowheads in all panels of Figure 4). These cells appear to cluster toward the neuropil facing edge of the cell somata layer in the pBucL.

\section{pNPY expression in the Optic Lobe and}

Peduncle Complex is highly regionspecific and sparse

Within the peduncle complex, located adjacent to the optic lobe on top of the optic tract, we observed a small cluster of pNPY positive neuronal somata in the olfactory lobe (Figure 5a, and 5b) (type 9 in Table 1). Specifically, this cluster of cells appears to be situated in the neuronal somata layer at the junction of the anterior and medial olfactory lobules (Figure 5a).

Neurons expressing pNPY can be seen in some cell clusters of the optic lobe
(Figure 5d) (type 10 in Table 1). These cells were scattered throughout the optic lobe. These cells share morphologically similarity with some of the NPY-IR optic lobe neuronal somata observed previously (Suzuki et al., 2002). No pNPY positive neural processes are visible in the optic lobes.

\section{Discussion}

\section{NPY in molluscs}

Detailed comparative analyses of the Octopus Neuropeptide Y precursor (Figure 1a) throughout metazoans builds on existing studies that have been primarily limited to the chordate lineage (Larhammar, 1996). Our analyses confirm that NPY may have originated in the common ancestor of all bilaterians. This conclusion is consistent with the computational cluster mapping (Jékely, 2013) of ancient neuropeptide families, indicating that the NPY protein family emerged in the Urbilateria. Our multiple sequence alignments reveal one mutation that is unique to the cephalopod lineage. Instead of the highly conserved dibasic cleavage site (KR) that follows the glycine $(\mathrm{G})$ residue, an arginine $(\mathrm{R})$ residue is 
found at position 78. In the cephalopods, this residue is followed by a serine $(\mathrm{S})$ (or an aspartic acid (D) in N. pompilius). The conserved dibasic cleavage site is where posttranslational cleavage enzymes recognize and cut the prepropeptide before subsequent amidation. The variation here in cephalopod pNPY sequences may, therefore, indicate that the enzymes required to convert $\mathrm{pNPY}$ into bioactive NPY may be different from those employed in other closely related lineages. Although monobasic (as opposed to dibasic) cleavage sites are not uncommon in secretory molecules, their presence in cephalopod NPY sequences appears to be unique among molluscs.

An additional amino acid sequence variation can be seen at position 76 in Figure 1A. The N-terminal tyrosine (Y) at this site is the origin of the name "Neuropeptide Y" (Tatemoto K Fau Carlquist et al., 1982) in deuterostomes. However, in the case of many protostomes, like Octopus, the N-terminal amino acid is a phenylalanine $(\mathrm{F})$. In some cases, like the insect Drosophila melanogaster (Fadda et al., 2019), researchers have changed the name to the possibly more appropriate "Neuropeptide F", but in this case, we will continue with the nomenclature of existing cephalopod NPY studies. Both phenylalanine and tyrosine possess hydrophobic side chains with the $\alpha$-carboxyl group of phenylalanine being more acidic (1.83 vs. $2.2 \mathrm{pKa}_{1}$ ) and its $\alpha$-ammonium ion being very slightly less acidic (9.13 vs. 9.11 $\mathrm{pKa}_{2}$ ) than those of tyrosine. The only major structural difference between the two residues is that the phenyl group of tyrosine is hydroxylated, but that of phenylalanine is not. Despite minor structural and chemical differences in the $\mathrm{N}$-terminal amino acids, functional studies across taxa show that this substitution at this site does not render the final product biologically inactive, nor does it dramatically change its physiological roles.

The alignments discussed above were used to generate a gene tree (Figure 1b) whose branches correspond with the predicted evolutionary history of particular animal lineages. This supports the scenario that pNPY sequences originally evolved in the common ancestor of protostomes and deuterostomes and 
subsequently radiated throughout characterized taxa without notable losses or duplications.

\section{pNPY expression in the Octopus} bimaculoides brain reveals potential novel circuitry

The most striking expression pattern of pNPY was found in the dorsal basal lobe (DBL), where densely clustered neurons of the posterior DBL (pDBL) layer project anteriorly toward (and in some cases through) the anterior DBL (aDBL) as seen in Figure 2a. Although some pNPY positive neuronal somata (Figure 3c, cell type 4) are found in the aDBL, the majority of the DBL pNPY positive neurons originate in the $\mathrm{pDBL}$ (Figure 3a-b, cell types 1-3). According to the Octopus brain atlas (Young, 1971), the majority of the pDBL efferents project downward toward the median basal lobe (MBL), whose neuronal somata are also pNPY positive. In our study, however, the most obvious of the large pNPY positive tracts project anteriorly toward the anterior basal lobes (ABL), subfrontal lobes (SubFrL), and posterior buccal lobes (pBucL ), or angle upward toward the subvertical lobe (SubVL).
NPY signaling between the pDBL and SubVL (part of the VL visual memory circuit) may occur in both directions, as we also saw pNPY positive neurons in the SubVL (Figure 3e) and bidirectional tracts between the SubVL and the pDBL have been described previously (Young, 1971). Based on their positions, a possible role for the pNPY positive projections between the pDBL and SubVL could be in processing or transmitting visual information, perhaps acting as an "integration" site between visual (VL circuit), tactile (SubFrL/ABL/pBucL ), and ultimately motor centers.

To date, there are no described direct functional relationships between DBL neurons and the ABL, SubFrL, or pBucL, but our study has revealed clear evidence of pNPY projections originating in the DBL, terminating at or near each of these structures. The coronal brain crosssection in Figure $2 d$ further verified that the long processes of $\mathrm{pNPY}$ positive DBL neurons were scattered throughout the basal lobes, indicating multiple targets from the same $\mathrm{DBL}$ region. The $\mathrm{ABL}$ has been implicated in the coordination of head and arms when handling prey 
(Young, 1971), and the pBucL and SubFrL are both key relay centers in the tactile learning and memory system, which is also imperative to prey capture. Currently, the only described inputs to the pBucL are the lateral inferior frontal (IIFL) and SubFrL (Young, 1971) of the tactile memory circuit and the axial nerve cords of the arms. Here we propose additional inputs from the long projections from the DBL, which may be using NPY as a signaling molecule to modulate the activity of other structures inextricably involved in memory and feeding behaviors (Di Cosmo et al., 2014).

The abundant expression of pNPY encoding transcripts in both the large cells and the amacrine cells of the pBucL (Figure 2b-c and Figure 4) further suggests a role for NPY in this structure. Efferent tracts from the pBucL project back to the axial nerve cord and the SubFrL, so in this instance, NPY might be mediating a role for the pBucL as a second "integration center" between the tactile memory circuit and feeding behaviors elicited in the arms. Additional potential outputs for the $\mathrm{pNPY}$ positive neurons of the $\mathrm{pDBL}$ and $\mathrm{MBL}$ are the magnocellular and subesophageal lobes. Although there appears to be no pNPY expression in either of these locations, activities in these lobes may still be mediated by presynaptic pNPY positive neurons of the supraesophageal lobes.

Finally, the extrasomatic pNPY mRNAs that localized to some (but not all) neurites in the brain (Figures 2, 3, and 4) suggest that a select population of neurons transport mRNA along the axon, perhaps to synaptic regions (Puthanveettil et al., 2013). This may indicate a function of NPY transcripts in these areas, as these mRNAs could be locally translated and processed at the synapse instead requiring transport of synthesized protein down the length of the neurite after translation. The region-specific extrasomatic mRNAs may expedite fast and recoded responses specific to the highly regionalized brain structures, as was recently highlighted in squid (Vallecillo-Viejo et al., 2020).

As noted above, a role for NPY in food-related and motivational state learning and memory has also been characterized in larval neural circuits (Rohwedder et al., 2015) and the mushroom bodies of adult (Krashes et al., 2009) fruit flies, but one must use caution 
in making comparisons across such evolutionary distances. Despite the existence of sophisticated neuronal memory circuitry in flies and octopuses, these neural circuits very likely evolved independently of one another, thus requiring independent recruitment of any molecular commonalities (Moroz, 2009; Yoshida et al., 2015). Still, the possibility of parallel implementation of NPY for molecular mediation of memory circuitry across distant lineages suggests some unknown characteristic of NPY that facilitates its candidacy as a signaling molecule in memory circuit integration. Further examination of functional roles for NPY in intermediate species (those that punctuate the branches on the evolutionary tree) between flies and cephalopods will likely reveal whether these independent recruitment events resulted from some inherently advantageous and conserved aspect of NPY or are simply random.

\section{NPY expression in the Octopus brain} and peduncle complex is functionally inconclusive

The entire DBL region of the Octopus brain receives input from the optic lobes via the optic tract, but projections from the olfactory lobe specifically target the pDBL and not the aDBL. It is possible that some of the large pNPY positive tracts that originate in the pDBL project back toward the ipsilateral middle olfactory lobule (Messenger, 1967). Experimental studies have indeed shown that degeneration of the pDBL neurons induces optic gland enlargement and the onset of reproductive processes (Wells et al., 1959), suggesting an integral role for $\mathrm{pDBL}$ neurons in the regulation of reproduction. Given the generally conserved role for NPY in feeding and the apparent interplay between the pDBL and the optic gland via the olfactory lobe, it is possible that the abundant pNPY transcript expression in the pDBL and efferent tracts might be involved in maintaining feeding behaviors while blocking the animal's transition to reproductive life stages in the olfactory lobe as suggested previously (Di Cristo et al., 2017).

Based on existing models for the role of NPY in Octopus (Di Cristo et al., 2017), we predicted that pNPY transcripts would be expressed in the olfactory lobe of the juvenile adult male octopuses used for this study. We consistently identified a 
small cluster of pNPY-positive neurons at the junction of the middle and anterior olfactory lobules (Figure 5 a and b). The neuronal somata expressing $\mathrm{pNPY}$ in the olfactory lobe appear to be elongated ovals with projections pointed toward the neuropil of the middle olfactory lobule. These pNPY positive cell clusters were quite small and lacked the dramatically abundant expression seen in the central brain tissues. However, it is imprudent to assume insignificance of the small cluster of pNPY expressing cells just because they are visually underwhelming. For example, there are only 20 or 26 (in female vs. male respectively) NPY/NPF expressing neurons in the entire nervous system of $D$. melanogaster, but a myriad of functions have been attributed to this small pool cells (Nässel et al., 2011). We are not suggesting that the small pool of NPY/NPF expressing neurons in flies bears any homology to any of the pNPY expressing cell populations of the Octopus brain, but highlighting the fact that in some cases, the number of cells involved in a physiological process does not directly correlate with the scope of their function. Our detection of a small cluster of pNPY mRNA expressing neurons in the olfactory lobes are therefore not inconsistent with the existing hypothesis that NPY may act as a signaling molecule among the olfactory lobes, optic glands, and the brain (Di Cosmo and Polese 2014) (via the olfactory nerve (Young, 1971)).

Interestingly, the expression patterns of pNPY mRNAs were different from that of NPY protein localization studies using immunohistochemistry (Suzuki et al., 2002). NPYimmunoreactive (NPY-IR) cell somata and fibers were previously identified throughout the whole peduncle and optic lobe complexes, including in the optic glands. Localization patterns of transcripts encoding pNPY detected by in situ hybridization were restricted to the middle olfactory lobe cluster mentioned above. Another noted inconsistency between our in situ hybridization mapping and NPY immunohistochemical studies (Suzuki et $a l ., 2002)$ is the stark difference between the distribution of NPY positive cells and fibers in the optic lobes (Figure 5c and d). This could be due to the fact that in this study, we used only juvenile $O$. bimaculoides males. However, one might expect to see different NPY expression in 
the optic lobes of immature females, similarly to the NPY-IR expression previously reported (Suzuki et al., 2002).

There are further possible explanations for the NPY distribution discrepancy across studies. Because in situ hybridization only reveals mRNA localization, far more structures (mainly neuronal processes) were detected using immunohistochemistry (Suzuki et al., 2002) than by our in situ hybridization methods. Therefore, the discrepancy could be somewhat attributed to the limitations of each technique. pNPY or NPY protein might be very stable, negating a need for constant mRNA production and storage throughout the necessary tissues. This explanation, however, does not fit with the abundant expression of pNPY mRNA in the brain, which indicates that pNPY mRNA exists at relatively high levels in specific lobes. An additional possibility for the discrepancies in the distribution of pNPY in this study and NPY-IR cells in previous studies (Suzuki et al., 2002) is the noted cross-reactivity of their antibody with the related peptide, Peptide YY (PYY). In this case, our study provides a method to positively distinguish the P-YY neurons from the true pNPY expressing neurons of the Octopus nervous system.

\section{Conclusions}

Here we characterized the expression of the Neuropeptide Y prohormone in Octopus bimaculoides nervous system (an important reference species in evolutionary neuroscience (Albertin et al., 2012)), adding novel molecular and structural insights into the mechanisms controlling feeding and reproduction. We noted a generally conserved putative active site, flanked by a minor lineage-specific sequence variation at the $\mathrm{N}$-terminal cleavage site in Octopus pNPY.

We have also identified the distinct expression of $\mathrm{pNPY}$ in specialized regions of the brain, including two potential "integration centers" where visual, tactile, and behavioral neural circuitry converge: the dorsal basal lobe and the posterior buccal lobe. Each of these possible integration centers can produce pNPY as the signaling molecule for communications between the olfactory lobe (which controls reproductive 
behaviors), subvertical and subfrontal lobes (employed in visual and tactile learning and memory respectively), and the anterior basal lobes and axial nerve cords (both implicated in feeding behaviors). These centers and their accessory structures may control feeding and reproductive behaviors, using NPY as the signaling peptide with multiple integrative functions. The extrasomatic localization of pNPY mRNA may add an additional layer of temporal regulation of the complex behaviors in cephalopods.

The partial overlap of immunohistochemical and in situ hybridization localization provides intriguing bases for functional and temporal hypotheses about the role of NPY in Octopus nervous systems. If the current models (Di Cosmo and Polese 2014) are accurate, then it would also follow that the pNPY expressing neurons of the olfactory lobe exert an inhibitory effect on the optic gland and the onset of reproductive behaviors. NPY synthesis and in-vivo administration (or manipulation of the predicted NPY receptor) and subsequent behavioral and physiological characterization would help us to understand the exact regulatory role of NPY in Octopus. Behavioral and physiological characterization of Octopus after exogenous application of NPY would help us determine whether the primary function of NPY expressing neurons is to regulate a component of the memory circuitry, mediate the transition between feeding and reproduction life stages, or/and something yet un-proposed, suggesting a possible pleiotropic role played by NPY in different regions of the nervous system. 


\section{Data Availability}

The data that support the findings of this study are available from the corresponding author upon reasonable request.

\section{Author contributions}

G.C.W. and L.L.M.: Conceptualization, Data curation, Formal analysis, Investigation, Methodology, Software, Validation, Visualization, Writing original draft, Writing-review \& editing. L.L.M.: Funding Acquisition, Project Administration, Resources, and Supervision. G.P. and A.DC. Validation, Writing-review \& editing

\section{Conflict of Interests}

The authors have no conflict of interest to declare.

\section{Acknowledgments}

The authors would like to thank Yelena Bobkova and Tatiana Moroz for technical laboratory assistance, and Dr. Caleb Bostwick for editing. This work was supported by the Human Frontiers Science Program (RGP0060/2017) and National Science Foundation (grants 1146575, 1557923, 1548121 and 1645219 to L.L.M); we also thank the Compagnia di San Paolo for supporting this study by a "Single Center Research Grant in Neuroscience" (Protocol 29-11 A.DC). 


\section{References}

Albers, H. E. and C. F. Ferris (1984). "Neuropeptide Y: Role in light-dark cycle entrainment

4 of hamster circadian rhythms." Neuroscience Letters 50(1): 163-168.

Albertin, C. B., Bonnaud, L., Brown, C. T., Crookes-Goodson, W. J., da Fonseca, R.R., Di Cristo, C., Dilkes, B. P., Edsinger-Gonzales, E., Freeman, R. M., Jr., Hanlon. R.T., Koenig, K.M., Lindgren, A. R., Martindalem M. Q., Minx, P., Moroz, L. L., Nodl, M. T., Nyholm, S. V., Ogura, A., Pungor, J. R., Rosenthal, J. J., Schwarz, E. M., Shigeno, S., Strugnell, J. M., Wollesen, T., Zhang, G., Ragsdale, C. W. (2012). "Cephalopod genomics: A plan of strategies and organization". Stand in Genomic Sciences 7(1): 175-188.

11 Altschul, S. F., W. Gish, W. Miller, E. W. Myers and D. J. Lipman (1990). "Basic local alignment search tool.” Journal of Molecular Biology 215(3): 403-410.

Antonov, I., T. Ha, I. Antonova, L. L. Moroz and R. D. Hawkins (2007). "Role of nitric oxide in classical conditioning of siphon withdrawal in Aplysia." J Neurosci 27(41): 10993-11002.

Beck, B. (2006). "Neuropeptide Y in normal eating and in genetic and dietary-induced obesity." Philosophical transactions of the Royal Society of London. Series B, Biological sciences 361(1471): 1159-1185.

18 Boyle, P. R. (1983). Eldone cirrhosa. Cephalopod Life Cycles. P. R. Boyle. London, 19 Academic Press 1: 365-386.

20 Christie, A. E., M. C. Chapline, J. M. Jackson, J. K. Dowda, N. Hartline, S. R. Malecha and P. H. Lenz (2011). "Identification, tissue distribution and orexigenic activity of neuropeptide F (NPF) in penaeid shrimp." The Journal of experimental biology 214(Pt 8): 1386-1396.

Cox, H. M. (1993). The Role of NPY and Related Peptides in the Control of Gastrointestinal Function. The Biology of Neuropeptide Y and Related Peptides. W. F. Colmers and C. Wahlestedt. Totowa, NJ, Humana Press: 273-313.

de Jong-Brink, M., A. ter Maat and C. P. Tensen (2001). "NPY in invertebrates: molecular answers to altered functions during evolution." Peptides 22(3): 309-315.

De Lisa, E., M. Paolucci and A. Di Cosmo (2012). "Conservative Nature of Oestradiol Signalling Pathways in the Brain Lobes of Octopus vulgaris Involved in Reproduction, Learning and Motor Coordination.” Journal of Neuroendocrinology 24(2): 275-284.

Di Cosmo, A. and C. Di Cristo (1998). "Neuropeptidergic control of the optic gland of Neurology 398(1): 1-12.

34 Di Cosmo, A. and G. Polese (2013). Molluscan Bioactive Peptides. Handbook of Elsevier.

Di Cosmo, A. and G. Polese (2014). Cephalopods Meet Neuroecology: The Role of

38 Chemoreception in Octopus vulgaris Reproductive Behaviour. Neuroecology and 
neuroethology in Molluscs - the Interface between Behaviour and Environment. Hauppauge, NY, NOVA Science Publisher: 117-132.

Di Cosmo, A. and G. Polese (2016). "Neuroendocrine-Immune Systems Response to Environmental Stressors in the Cephalopod Octopus vulgaris." Frontiers in Physiology 7(434).

Di Cristo, C. (2013). "Nervous control of reproduction in Octopus vulgaris: a new model." Invertebrate Neuroscience 13(1): 27-34.

Di Cristo, C., E. De Lisa and A. Di Cosmo (2009). "Control of GnRH expression in the olfactory lobe of Octopus vulgaris." Peptides 30(3): 538-544.

Di Cristo, C. and J. M. Koene (2017). Neurobiology of Reproduction in Molluscs: Mechanisms and Evolution. The Oxford Handbook of Invertebrate Neurobiology. J. H. Byrne. New York, NY, Oxford University Press.

Edgar, R. C. (2004). "MUSCLE: a multiple sequence alignment method with reduced time and space complexity." BMC Bioinformatics 5: 113.

Erion, R., A. N. King, G. Wu, J. B. Hogenesch and A. Sehgal (2016). "Neural clocks and Neuropeptide F/Y regulate circadian gene expression in a peripheral metabolic tissue." eLife 5: e13552.

Erion, R., A. N. King, G. Wu, J. B. Hogenesch and A. Sehgal (2016). "Neural clocks and Neuropeptide F/Y regulate circadian gene expression in a peripheral metabolic tissue." eLife 5.

Fadda, M., I. Hasakiogullari, L. Temmerman, I. Beets, S. Zels and L. Schoofs (2019).

60 "Regulation of Feeding and Metabolism by Neuropeptide F and Short Neuropeptide F in

61 Invertebrates." Frontiers in Endocrinology 10: 64.

Hanson, E. S. and M. F. Dallman (1995). "Neuropeptide Y (NPY) may integrate responses of hypothalamic feeding systems and the hypothalamo-pituitary-adrenal axis." Journal of 64 Neuroendocrinology 7: 273-279.

65 Holzer, P., F. Reichmann and A. Farzi (2012). "Neuropeptide Y, peptide YY and pancreatic 66 polypeptide in the gut-brain axis." Neuropeptides 46(6): 261-274. Jékely, G. (2013). "Global view of the evolution and diversity of metazoan neuropeptide 68 signaling." Proc Natl Acad Sci U S A 110.

69 Jezzini, S. H., M. Bodnarova and L. L. Moroz (2005). "Two-color in situ hybridization in the 70 CNS of Aplysia californica." Journal of Neuroscience Methods 149(1): 15-25.

71 Jing, J., F. S. Vilim, C. C. Horn, V. Alexeeva, N. G. Hatcher, K. Sasaki, I. Yashina, Y. 72 Zhurov, I. Kupfermann, J. V. Sweedler and K. R. Weiss (2007). "From Hunger to Satiety: 73 Reconfiguration of a Feeding Network by Aplysia Neuropeptide Y." The Journal of 74 Neuroscience 27(13): 3490.

75 Juárez, O. E., L. López-Galindo, L. Pérez-Carrasco, A. Lago-Lestón, C. Rosas, A. Di Cosmo 76 and C. E. Galindo-Sánchez (2019). "Octopus maya white body show sex-specific 
transcriptomic profiles during the reproductive phase, with high differentiation in signaling pathways." PLOS ONE 14(5): e0216982.

Krashes, M. J., S. DasGupta, A. Vreede, B. White, J. D. Armstrong and S. Waddell (2009). "A Neural Circuit Mechanism Integrating Motivational State with Memory Expression in Drosophila." Cell 139(2): 416-427.

82 Kumar, S., G. Stecher and K. Tamura (2016). "MEGA7: Molecular Evolutionary Genetics 83 Analysis Version 7.0 for Bigger Datasets." Mol Biol Evol 33(7): 1870-1874.

84 Larhammar, D. (1996). "Evolution of neuropeptide Y, peptide YY and pancreatic 85 polypeptide." Regulatory Peptides 62(1): 1-11.

86 Lee, G., J. H. Bahn and J. H. Park (2006). "Sex- and clock-controlled expression of the neuropeptide F gene in Drosophila." Proceedings of the National Academy of Sciences of the United States of America 103(33): 12580-12585.

Lee, S., Y.-J. Kim and W. D. Jones (2017). “Central peptidergic modulation of peripheral olfactory responses.” BMC Biology 15(1): 35.

91 Letunic, I. and P. Bork (2018). "20 years of the SMART protein domain annotation resource." Nucleic Acids Res 46(D1): D493-D496.

93 Letunic, I., T. Doerks and P. Bork (2015). "SMART: recent updates, new developments and 94 status in 2015." Nucleic Acids Res 43(Database issue): D257-260.

95 Messenger, J. B. (1967). "The Peduncle Lobe: A Visuo-Motor Centre in Octopus." 96 Proceedings of the Royal Society B: Biological Sciences 167(1008): 225-251.

97 Moroz, L. L. (2009). "On the independent origins of complex brains and neurons." Brain 98 Behav Evol 74(3): 177-190

99 Moroz, L. L. and A. B. Kohn (2013). "Single-neuron transcriptome and methylome 100 sequencing for epigenomic analysis of aging." Methods in Molecular Biology 1048: 323101352.

102 Nässel, D. R. and C. Wegener (2011). “A comparative review of short and long neuropeptide 103 F signaling in invertebrates: Any similarities to vertebrate neuropeptide $\mathrm{Y}$ signaling?" 104 Peptides 32(6): 1335-1355.

105 Polese, G., C. Bertapelle and A. Di Cosmo (2015). "Role of olfaction in Octopus vulgaris 106 reproduction." General and Comparative Endocrinology 210: 55-62.

107 Puthanveettil, S. V., Antonov, I., Kalachikov, S., Rajasethupathy, P., Choi, Y. B., Kohn, A. 108 B., Citarella, M., Yu, F., Karl, K. A., Kinet, M., Morozova, I., Russo, J. J., Ju, J., Moroz, L. 109 L., Kandel, E. R. (2013). A strategy to capture and characterize the synaptic transcriptome. 110 Proc Natl Acad Sci U S A 110(18):7464-7469.

111 Redrobe, J. P., J. A. Dumont Y Fau - St-Pierre, R. St-Pierre Ja Fau - Quirion and R. Quirion 112 "Multiple receptors for neuropeptide $\mathrm{Y}$ in the hippocampus: putative roles in seizures and 113 cognition." (0006-8993 (Print)). 
114 Rohwedder, A., M. Selcho, B. Chassot and A. S. Thum (2015). "Neuropeptide F neurons

115 modulate sugar reward during associative olfactory learning of Drosophila larvae." Journal

116 of Comparative Neurology 523(18): 2637-2664.

117 Ruffin, M.-P., P. C. Even, M. El-Ghissassi and S. Nicolaidis (1997). "Metabolic Action of

118 Neuropeptide Y in Relation to Its Effect on Feeding." Physiology \& Behavior 62(6): 1259-

1191264.

120 Salomäki-Myftari, H., L. H. Vähätalo, L. Ailanen, S. Pietilä, A. Laiho, A. Hänninen, J.-P. 121 Pursiheimo, E. Munukka, A. Rintala, E. Savontaus, U. Pesonen and M. Koulu (2016).

122 "Neuropeptide Y Overexpressing Female and Male Mice Show Divergent Metabolic but Not

123 Gut Microbial Responses to Prenatal Metformin Exposure.” PLOS ONE 11(9): e0163805.

124 Suzuki, H., T. Yamamoto, M. Inenaga and H. Uemura (2000). "Galanin-immunoreactive 125 neuronal system and colocalization with serotonin in the optic lobe and peduncle complex of 126 the octopus (Octopus vulgaris).” Brain Research 865(2): 168-176.

127 Suzuki, H., T. F. Yamamoto, M. Nakagawa and H. Uemura (2002). "Neuropeptide Y128 immunoreactive neuronal system and colocalization with FMRFamide in the optic lobe and 129 peduncle complex of the octopus (Octopus vulgaris)." Cell Tissue Res. 307: 255-264.

130 Tatemoto, K. (1982). "Neuropeptide Y: complete amino acid sequence of the brain peptide." 131 Proc Natl Acad Sci, U. S. A.(0027-8424 (Print)).

132 Tatemoto K Fau - Carlquist, M., V. Carlquist M Fau - Mutt and V. Mutt (1982).

133 "Neuropeptide Y--a novel brain peptide with structural similarities to peptide YY and 134 pancreatic polypeptide.” Nature(0028-0836 (Print)).

135 Thorsell, A. and M. Heilig (2001). "Diverse functions of neuropeptide Y revealed using 136 genetically modified animals." Neuropeptides 36(2-3): 182-193.

137 Thorsell, A. and M. Heilig (2002). "Diverse functions of neuropeptide Y revealed using 138 genetically modified animals.” Neuropeptides 36(2): 182-193.

139 Wahlestedt, C., E. M. Pich, G. F. Koob, F. Yee and M. Heilig (1993). "Modulation of anxiety 140 and neuropeptide Y-Y1 receptors by antisense oligodeoxynucleotides." Science 259(5094): 141528.

142 Walker, P., M. Grouzmann E Fau - Burnier, B. Burnier M Fau - Waeber and B. Waeber 143 (1991). "The role of neuropeptide Y in cardiovascular regulation." Trends Pharmacol Sci. 144 12: 111-115.

145 Wang, X., J. Miao, P. Liu and L. Pan (2017). "Role of neuropeptide F in regulating filter 146 feeding of Manila clam, Ruditapes philippinarum." Comparative Biochemistry and 147 Physiology Part B: Biochemistry and Molecular Biology 205: 30-38.

148 Wang, Z. Y. and C. Ragsdale (2019). Cephalopod Nervous System Organization, Oxford 149 University Press.

150 Wells, M. J. (1978). Octopus: Physiology and Behaviour of an Advanced Invertebrate. 151 London, England, Chapman and Hall. 
152 Wells, M. J. and J. Wells (1959). “Hormonal Control of Sexual Maturity in Octopus.” Journal 153 of Experimental Biology 36(1): 1.

154 Whelan, S. and N. Goldman (2001). "A general empirical model of protein evolution derived 155 from multiple protein families using a maximum-likelihood approach.” Mol Biol Evol. 18: 156 691-699.

157 Wodinsky, J. (1977). "Hormonal Inhibition of Feeding and Death in Octopus: Control by 158 Optic Gland Secretion.” Science 198: 948.

159 Wu, Q., T. Wen, G. Lee, J. H. Park, H. N. Cai and P. Shen (2003). "Developmental Control 160 of Foraging and Social Behavior by the Drosophila Neuropeptide Y-like System.” Neuron 161 39(1): 147-161.

162 Yannielli, P. C. and M. E. Harrington (2001). "Neuropeptide Y in the mammalian circadian 163 system: effects on light-induced circadian responses." Peptides 22(3): 547-556.

164 Yoshida, M. A., Ogura, A., Ikeo, K., Shigeno, S., Moritaki, T., Winters, G. C., Kohn, A. B., 165 Moroz, L. L. (2015). Molecular Evidence for Convergence and Parallelism in Evolution of 166 Complex Brains of Cephalopod Molluscs: Insights from Visual Systems. Integr Comp Biol 167 55(6): 1070-1083

168 Young, J. Z. (1971). The anatomy of the nervous system of Octopus vulgaris. Oxford, 169 Clarendon Press. 
172 Table 1. Cell morphology of pNPY transcript expressing neurons.

\begin{tabular}{|c|c|c|c|c|c|}
\hline & $\begin{array}{l}\text { Veuronal Cell Shapes in } \\
\text { Dorsal Basal, Median } \\
\text { Basal, and Subvertical } \\
\text { Lobes }\end{array}$ & Cell Size & Location & Figure (s) & $\begin{array}{l}\text { Corresponding Cell } \\
\text { type in } O . \text { vulgaris } \\
\text { (Young, 1971) }\end{array}$ \\
\hline 1 & $\begin{array}{l}\text { Long oval with very large } \\
\text { projections }\end{array}$ & $\begin{array}{l}\sim 20 \quad \mu \mathrm{m} \\
\text { soma, up to } \\
\sim 2 \mathrm{~mm} \text { long } \\
\text { projection }\end{array}$ & $\begin{array}{lr}\text { Posterior } & \text { Dorsal } \\
\text { Basal } & \text { Lobe } \\
\text { (pDBL) } & \end{array}$ & $\begin{array}{l}\text { Projection: } \\
\text { 3a, 3b, 3c-- } \\
\text { Open } \\
\text { Arrows; } \\
\text { Soma: 3b } \\
\text { long closed } \\
\text { arrow }\end{array}$ & $\begin{array}{l}\text { Large cells of pDBL } \\
(\sim 4000 \text { total cells } \\
>10 \mu \mathrm{m} \text { diameter })\end{array}$ \\
\hline 2 & Irregular triangular shape & $5-8 \mu \mathrm{m}$ & $\begin{array}{lr}\text { Posterior } & \text { Dorsal } \\
\text { Basal } & \text { Lobe } \\
\text { (pDBL) } & \\
\text { - Prox. to subVL }\end{array}$ & $\begin{array}{l}3 \mathrm{e}, \quad 3 \mathrm{~h} \\
\text { Chevron }\end{array}$ & \multirow{2}{*}{$\begin{array}{l}\text { Medium cells of } \\
\text { pDBL }(\sim 375,000 \\
\text { total cells } 5-10 \mu \mathrm{m} \\
\text { diameter }) \\
\text { Medium cells of } \\
\text { pDBL }(\sim 375,000 \\
\text { total cells } 5-10 \mu \mathrm{m} \\
\text { diameter })\end{array}$} \\
\hline 3 & $\begin{array}{l}\text { Irregular teardrop shape } \\
\text { with short projection } \\
\text { (projection approx.. half- } \\
\text { length of soma) }\end{array}$ & $8-10 \mu \mathrm{m}$ & $\begin{array}{lr}\text { Posterior } & \text { Dorsal } \\
\text { Basal } & \text { Lobe } \\
\text { (pDBL) } & \\
\text { - Prox. to subVL }\end{array}$ & $\begin{array}{l}3 \mathrm{e}, \quad 3 \mathrm{~h}- \\
\text { Closed } \\
\text { Arrowhead }\end{array}$ & \\
\hline 4 & $\begin{array}{l}\text { Tapered oval (guitar pick) } \\
\text { shape, some visible } \\
\text { punctate projections }\end{array}$ & $\begin{array}{l}12-15 \mu \mathrm{m} \\
\text { soma, } \sim 50- \\
100 \quad \mu \mathrm{m} \\
\text { projection } \\
\text { (if visible) }\end{array}$ & $\begin{array}{lr}\text { Anterior } & \text { Dorsal } \\
\text { Basal } & \text { Lobe } \\
(\mathrm{aDBL}) & \end{array}$ & $\begin{array}{l}3 \mathrm{c}, \quad 3 \mathrm{~d} \\
\text { Closed } \\
\text { Arrows }\end{array}$ & $\begin{array}{l}\text { Large cells of } \\
\text { aDBL- no noted } \\
\text { total number in } \\
\text { aDBL }\end{array}$ \\
\hline 5 & $\begin{array}{l}\text { Long teardrop shape with } \\
\text { short projection if visible } \\
\text { (projection approx. half } \\
\text { the length of soma) }\end{array}$ & $20-30 \mu \mathrm{m}$ & $\begin{array}{l}\text { Median Basal } \\
\text { Lobe (MBL) }\end{array}$ & 3f-Arrow & $\begin{array}{l}\text { Large Cells of the } \\
\text { MBL }\end{array}$ \\
\hline \multirow[t]{2}{*}{6} & $\begin{array}{l}\text { Tapered oval (guitar pick) } \\
\text { shape }\end{array}$ & $\sim 10 \mu \mathrm{m}$ & $\begin{array}{l}\text { Posterior } \\
\text { Subvertical Lobe }\end{array}$ & $\begin{array}{l}\text { 3e - Open } \\
\text { Arrowhead }\end{array}$ & $\begin{array}{l}\text { Large cells of the } \\
\text { Posterior } \\
\text { Subvertical Lobe }\end{array}$ \\
\hline & $\begin{array}{l}\text { Neuronal Cell Shapes in } \\
\text { Posterior Buccal Lobe }\end{array}$ & Cell Size & Location & Figure(s) & $\begin{array}{l}\text { Corresponding } \\
\text { Cell type in } O \text {. } \\
\text { vulgaris (Young, } \\
\text { 1971) } \\
\end{array}$ \\
\hline 7 & $\begin{array}{l}\text { Teardrop w/ projection } \\
\text { toward neuropil (visible } \\
\text { projection approx. equal } \\
\text { to the length of soma) }\end{array}$ & $10-35 \mu \mathrm{m}$ & $\begin{array}{l}\text { Cell somata layer } \\
\text { of Posterior } \\
\text { Buccal Lobe }\end{array}$ & $\begin{array}{l}4-\quad \text { all } \\
\text { panels } \\
\text { Arrows }\end{array}$ & $\begin{array}{l}\text { Large cells of the } \\
\text { posterior buccal } \\
\text { lobes }\end{array}$ \\
\hline \multirow[t]{2}{*}{8} & Irregular oval shape & $5-10 \mu \mathrm{m}$ & $\begin{array}{l}\text { Cell somata layer } \\
\text { of } \quad \text { Posterior } \\
\text { Buccal Lobe }\end{array}$ & $\begin{array}{l}4-\quad \text { all } \\
\text { panels } \\
\text { Arrowhead }\end{array}$ & $\begin{array}{l}\text { Amacrine cells of } \\
\text { post. buc. lobe } \\
\text { (continuous w/ those } \\
\text { of subfr lobes) }\end{array}$ \\
\hline & $\begin{array}{l}\text { Neuronal Cell Shapes in } \\
\text { Optic Lobe and } \\
\text { Peduncle Complex }\end{array}$ & Cell Size & Location & Figure(s) & $\begin{array}{l}\text { Corresponding } \\
\text { Cell type in } O . \\
\text { vulgaris (Young, } \\
\text { 1971) }\end{array}$ \\
\hline 9 & Elongated oval & $5-10 \mu \mathrm{m}$ & $\begin{array}{l}\text { Anterior/Medial } \\
\text { Olfactory Lobe }\end{array}$ & $5 \mathrm{a}$ and $5 \mathrm{~b}$ & $\begin{array}{l}\text { Cell layer of the } \\
\text { Olfactory Lobules }\end{array}$ \\
\hline 10 & Tapered oval & $5-15 \mu \mathrm{m}$ & $\begin{array}{l}\text { OL cell islands- } \\
\text { few and scattered }\end{array}$ & $5 \mathrm{~d}$ & $\begin{array}{l}\text { Large cells of the } \\
\text { optic lobe cell } \\
\text { islands }\end{array}$ \\
\hline
\end{tabular}


173 Figure Legends

(a) H.sapiens

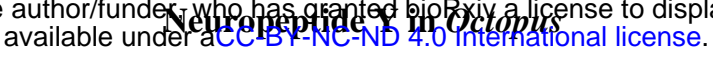

R. norvegicus

G.gallus

T.rubripes

$X .1$ aevis

O.mykiss

B.belcheri

B.mori

B.impatiens

L. anatina

C. teleta

L.stagnalis

A.californica

B.glabrata

T.pisana

C.gigas

N.pompilius

D.pealei

I.paradoxus

O.vulgaris

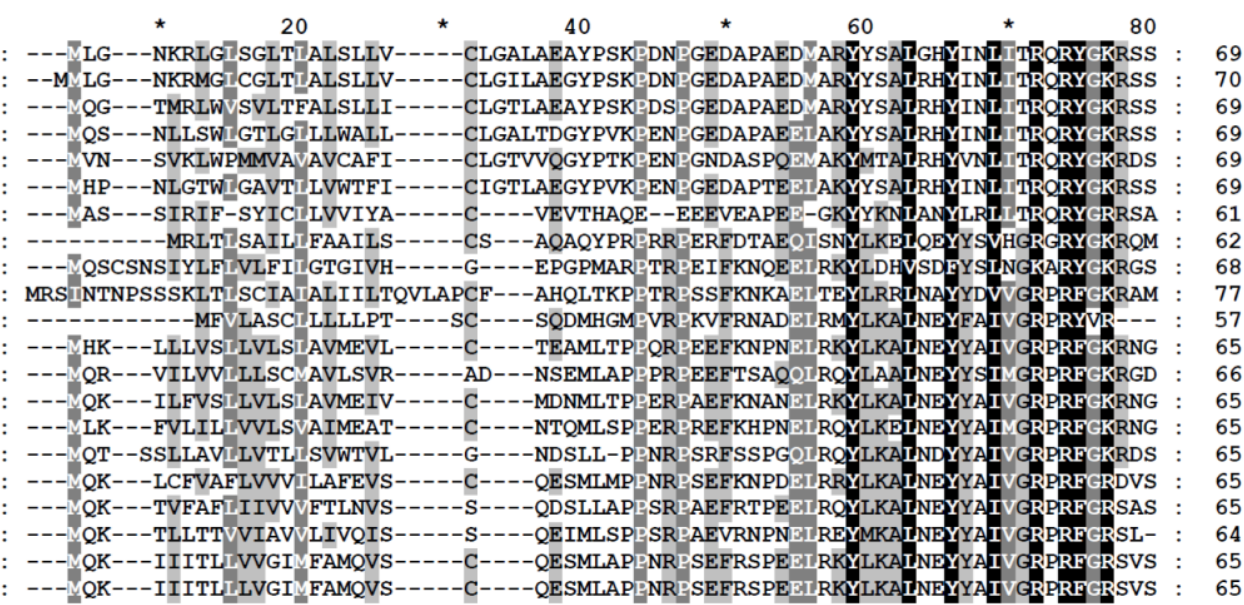

$\begin{array}{ccc}\text { Signal Peptide } & \text { Putative Active Site } \\ \text { Putative active site sequence: } & \end{array}$

MLAPPNRPSEFRSPEELRKYLKALNEYYAIVGRPRF-amide.

Cleavage Sites

(b)

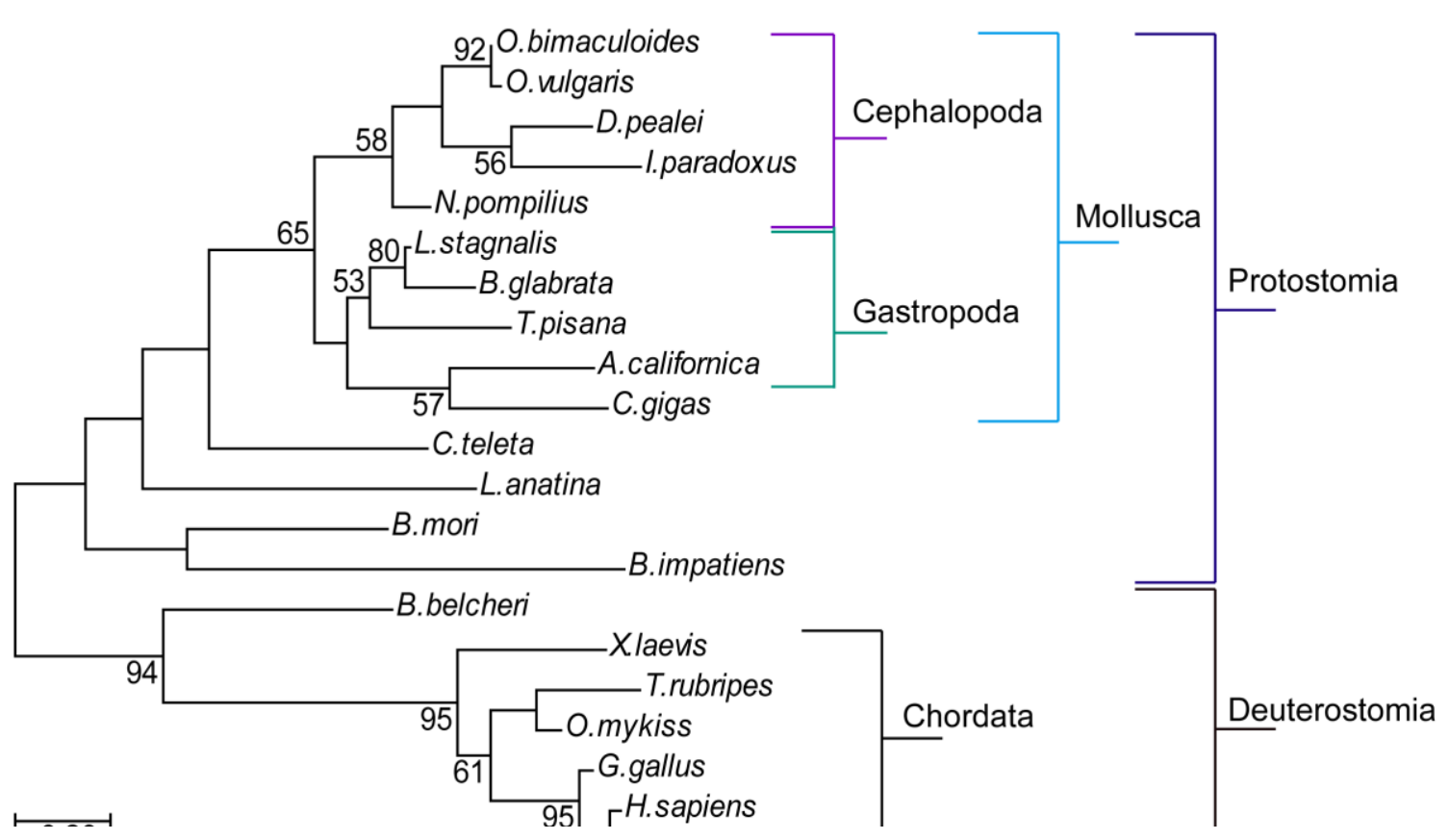

175 Figure 1. Multiple sequence alignment (a) and gene tree (b) for neuropeptide $\mathbf{Y}$ 176 precursor (pNPY) protein sequences illustrate evolutionary conservation. (a) depicts the

177 N-terminus of pNPY sequences with conserved residues aligned vertically using MUSCLE 
178 (Edgar, 2004) (note, entire sequences are not shown, as conservation is low or absent in the

179 C-terminus beyond the predicted active site). Below, the alignment is a schematic of

180 predicted domains of pNPY, based on predictions of SMART (Letunic et al., 2015, Letunic

181 et al., 2018) software web tools and confirmed mammalian (Porcine) pNPY active site 182 analyses (Tatemoto, 1982). Note that the glycine $(\mathrm{G})$ at position 77 (thin yellow bar in the

183 schematic) is followed by a dibasic cleavage site (KR) in the majority of taxa, but 184 cephalopods exhibit only a monobasic cleavage site $(\mathrm{R})$ in this position. Also note that in 185 molluscs, the amino acid at position 76 is a phenylalanine $(\mathrm{F})$ instead of the tyrosine $(\mathrm{Y})$ for 186 which the conserved polypeptide was originally named. (b) indicates a maximum likelihood 187 gene tree generated using the Whelan And Goldman model (Whelan et al., 2001). Taxon 188 branches are denoted in brackets on the right. Branches with bootstrap support over 50\% are 189 noted, and branch lengths correspond to the number of substitutions per site. These 190 evolutionary analyses were conducted in MEGA7 (Kumar et al., 2016). 

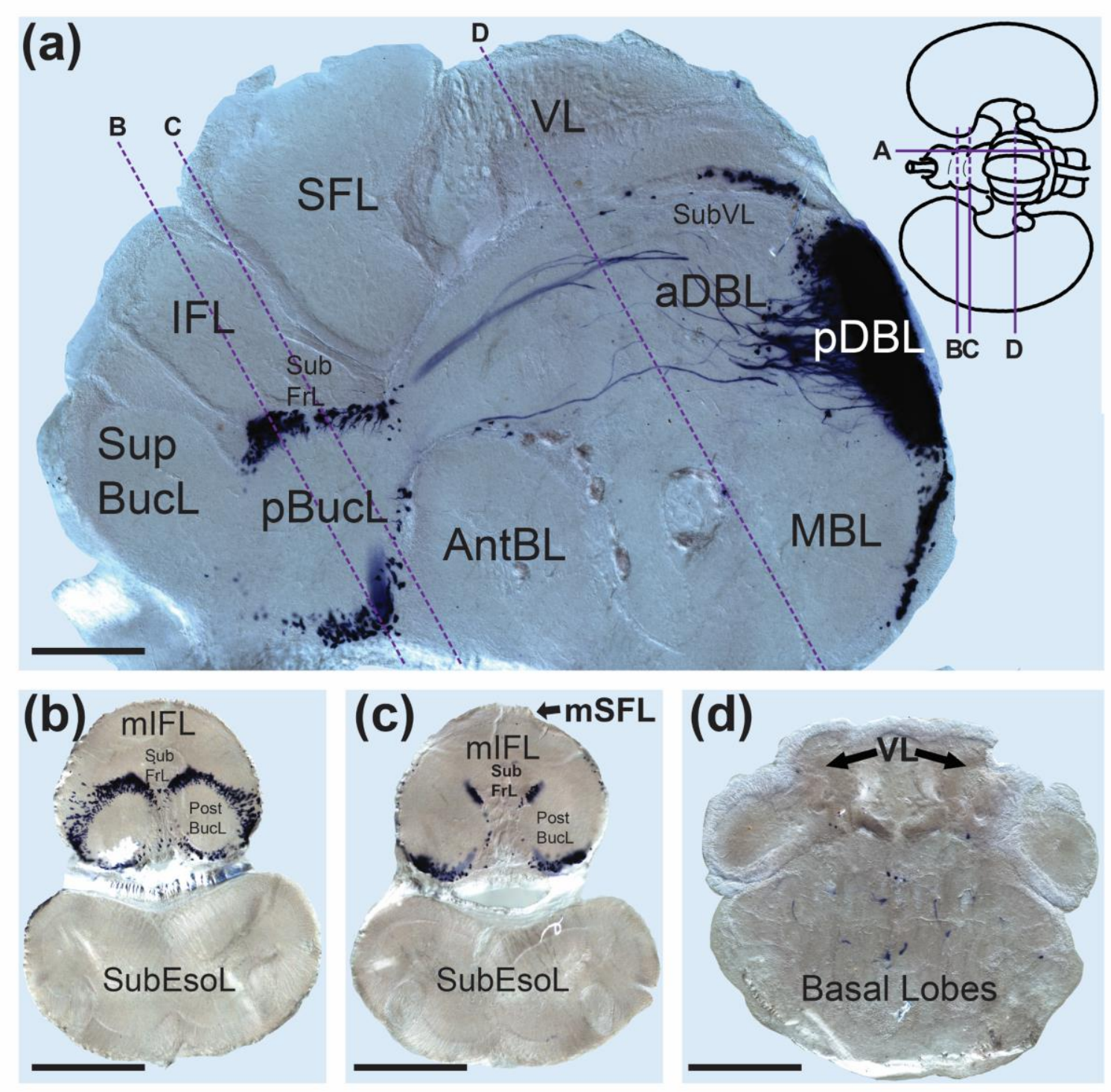

193 Figure 2. pNPY (neuropeptide Y encoding transcript) is expressed in multiple brain

194 lobes in $\boldsymbol{O}$. bimaculoides. (a) pNPY expression in a mediolateral brain slice in the sagittal

195 plane. pNPY probe localized to the subvertical lobe (SubVL), dorsal basal lobe (DBL: aDBL

196 is anterior, and pDBL is posterior), median basal lobe (MBL), posterior buccal lobe (pBucL),

197 and in few cells in the superior periphery of the anterior basal lobe (AntBL). Some neurons 
198 of the dorsal basal lobe appear to have long thick processes that project through the basal 199 lobe neuropil toward the frontal lobes. (b), (c), and (d) show brain slices in the diagonal 200 coronal plane and are in order of most anterior to most posterior. Slices in (b) and (c) include 201 both supra and sub-esophageal lobes and depict pNPY expression in the neuronal somata 202 layer of the posterior buccal lobe (pBucL). (d) depicts only supraesophageal lobes and 203 illustrates pNPY expression in cross-sections of the thick projections originating in the dorsal 204 basal lobes. Scale bar measurements are (a) $500 \mu \mathrm{m}$, (b and c) $1 \mathrm{~mm}$, and (d) $715 \mu \mathrm{m}$. 

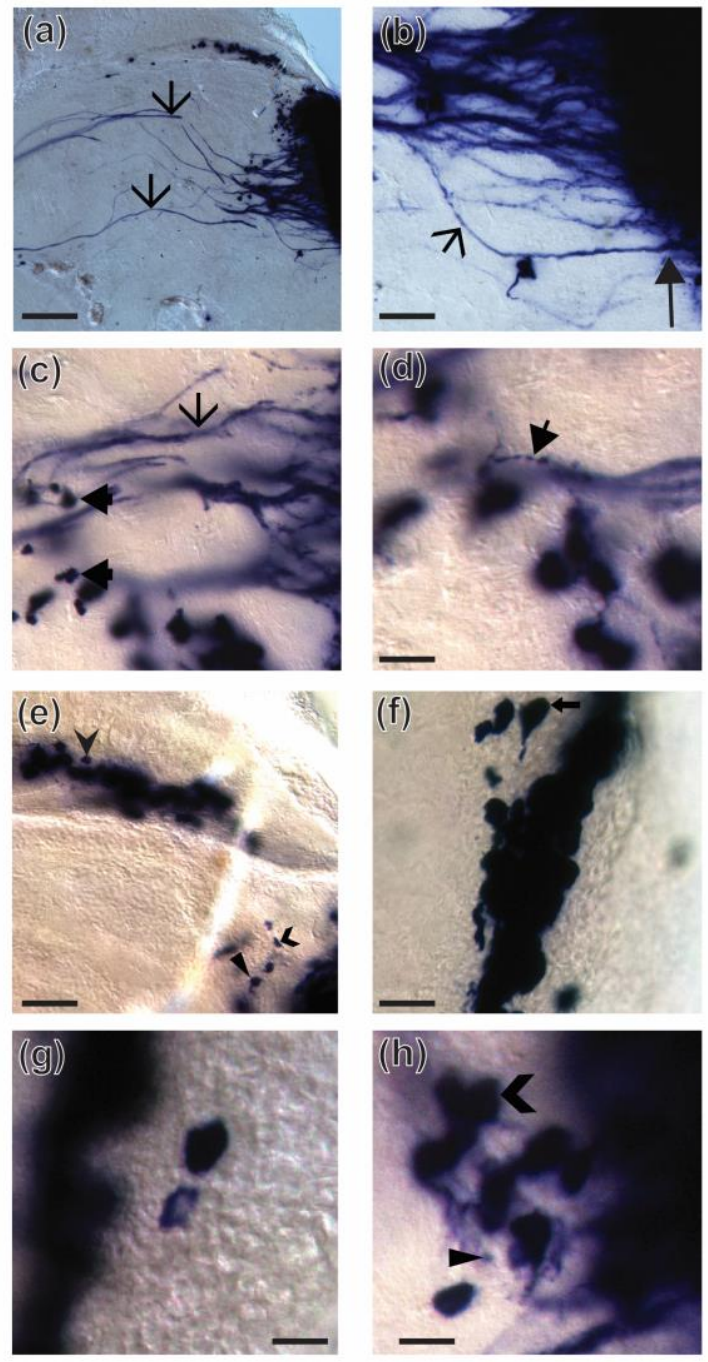

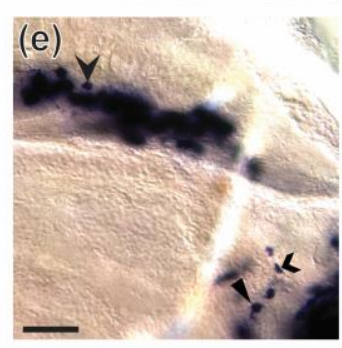

Figure 3. pNPY neurons of the posterior dorsal basal (DBL), median basal (MBL), and subvertical lobes (SubVL) exhibit morphological diversity. (a) through (d) highlight mRNAs of pNPY in axons projecting from the neurons of the DBL. The larger long projections (open arrows-type 1) appear to originate in the cell somata layer of the posterior DBL (pDBL) and can measure up to $2 \mathrm{~mm}$ in length and $20 \mu \mathrm{m}$ in diameter. The long arrow in (b) denotes the oval soma of the neuron, with a neurite (short open arrow) projecting at least 600 $\mu \mathrm{m}$ into the pDBL neuropil toward the anterior DBL (aDBL). The closed arrows in panel (c) and (d) depict cell type 4- in (c), the closed arrows indicate the neuronal somata that appear to be in the wall of neurons delineating the anterior and posterior regions of the DBL. pNPY transcripts are also present in punctate patches of thin, shorter processes illustrated in panel (d) (closed short arrow- the projection of type 4). Panels (b) through (h) also highlight the morphological diversity of neuronal somata of cells expressing pNPY 234 in the posterior region of the supraesophageal lobes. A total of six morphologically distinct neuronal subtypes were identified in the DBL, MBL, and SubVL. In (e) and (h), chevron arrowheads indicate type 2,

237 and closed arrowheads indicate type 3. In (e), the open arrowhead indicates type 6 cells. The 238 arrow in (f) indicates cell type 5. A summary of the neuronal somata diversity (pNPY neuron 239 types one though six) in this region can be found in Table 1 with arrowhead identifier 240 descriptions. Scale bar measurements are (a) $350 \mu \mathrm{m}$, (b) $100 \mu \mathrm{m}$, (c) $65 \mu \mathrm{m}$, (d \&f) $35 \mu \mathrm{m}$, 241 (e) $50 \mu \mathrm{m},(\mathrm{g} \& \mathrm{~h}) 20 \mu \mathrm{m}$. 

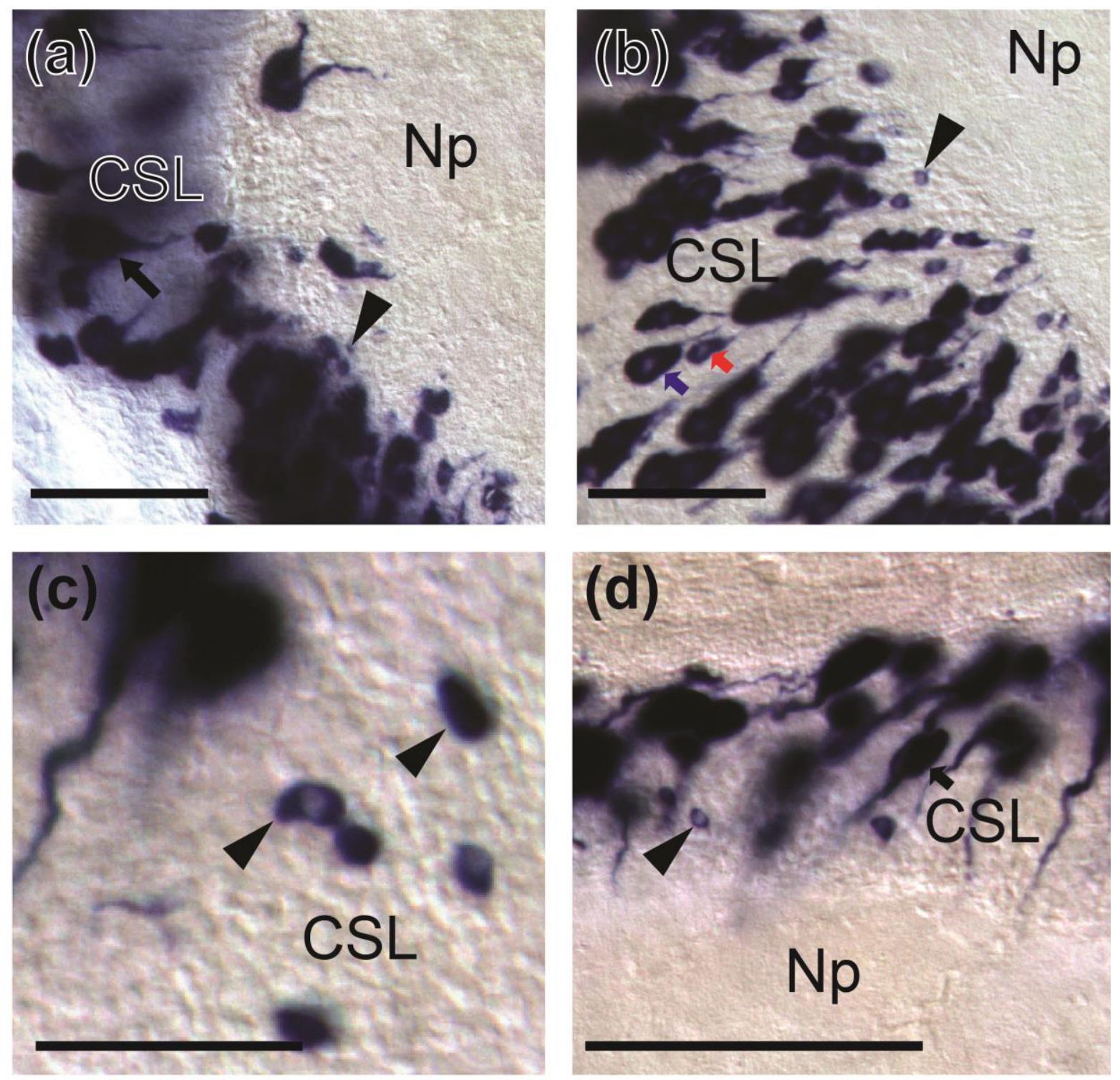

245 Figure 4. Two morphologically distinct subtypes of neurons express neuropeptide Y 246 precursor-encoding (pNPY) transcripts in the posterior buccal lobe (pBucL), as

247 illustrated in (a) through (d). (a) and (b) are of coronal slices, and panels (c) and (d) are from 248 sagittal slices. Arrows indicate pNPY neuron type eight, which possesses a large oval-shaped 249 soma in the cell somata layer (CSL) with a projection directed toward the neuropil (Np).

250 These neurons appear in a gradient of sizes ranging from about 10 to $35 \mu \mathrm{m}$ in length (not 251 including the projection). Examples of the variability in pNPY neuron type eight sizes are 
252 illustrated in (b), with a larger $(\sim 35 \mu \mathrm{m})$ cell soma indicated by a blue arrow, adjacent to a 253 smaller $(\sim 20 \mu \mathrm{m})$ cell soma indicated by a red arrow. The second neuronal subtype identified 254 in the pBucL are significantly smaller irregular ovals with no projections (pNPY neuronal 255 type nine). These are primarily positioned at the edge of the cell somata layer proximal to the 256 neuropil. A summary of the neuronal somata diversity (pNPY neuron types seven and eight) 257 in this region can be found in Table 1. All scale bars measure $100 \mu \mathrm{m}$. 

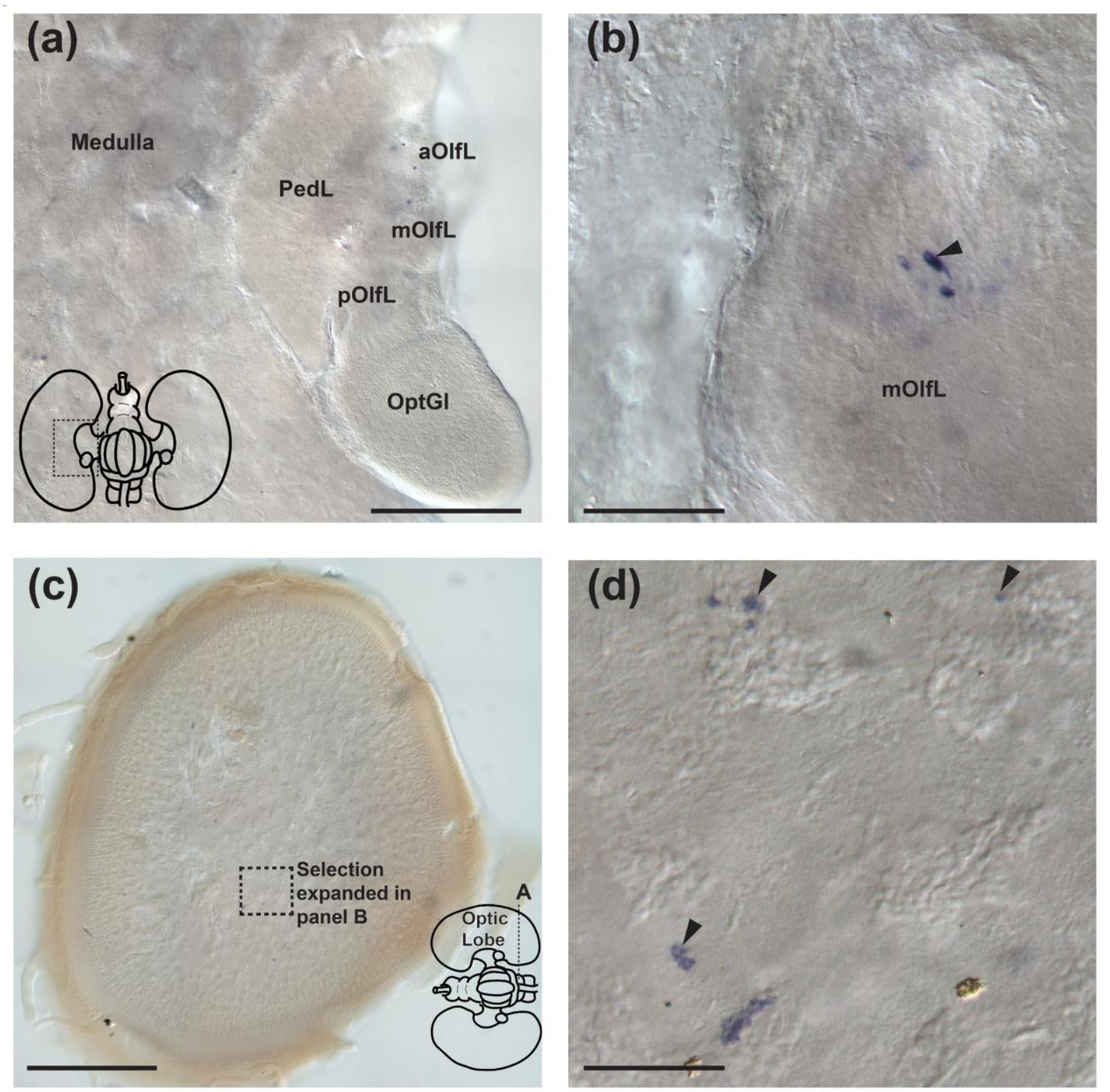

261 Figure 5. A small cluster of pNPY expressing neurons is visible in the middle olfactory

262 lobule, but pNPY positive neurons of the Optic Lobe (OL) are scarce and not immediately

263 apparent. Panel (a) illustrates the general location of pNPY positive neurons in the peduncle

264 complex, specifically along the border of the anterior and middle lobule of the olfactory lobe

265 (aOlfL and mOlfL respectively), which are anterior to the posterior olfactory lobule (pOlfL)

266 and the optic gland (OptGL). (b) further magnifies this preparation to illustrate the elongated

267 oval-shaped pNPY positive cells of the olfactory lobe, some of which have short visible 
268 processes. Panel (c) shows the overall infrequency of pNPY expressing neurons, as, at low 269 magnification, the section appears relatively free of obvious labeling. Panel (d) is a further 270 magnified view of the boxed section noted in (c). The arrowheads indicate tapered oval271 shaped neuronal somata ranging from about 5 to $15 \mu \mathrm{m}$ in diameter. A summary of the 272 neuronal somata diversity (pNPY neuron type nine and ten) in this region can be found in 273 Table 1. Scale bar measurements are (a and c) $500 \mu \mathrm{m}$, and (b and d) $50 \mu \mathrm{m}$. 